Technical Report 1123

\title{
Analysis of Infantry Situation Awareness Training Requirements
}

\author{
Laura D. Strater, Debra Jones, and Mica R. Endsley \\ SA Technologies
}

\author{
Infantry Forces Research Unit \\ Scott E. Graham, Chief
}

U.S. Army Research Institute for the Behavioral and Social Sciences 5001 Eleonhower Avenus, Alexandria, Virginia 22333-5600

\section{November 2001}

